\title{
Oesophageal clearance of small amounts of equal or less than one millilitre of acid
}

\author{
R Shaker, P J Kahrilas, W J Dodds, W J Hogan
}

\section{Division of \\ Gastroenterology, \\ Medical College of \\ Wisconsin, Froedtert \\ Memorial Lutheran \\ Hospital and VA Medical \\ Center, Milwaukee, \\ Wisconsin, USA \\ R Shaker \\ P J Kahrilas \\ W J Dodds \\ W J Hogan \\ Correspondence to: \\ Dr Reza Shaker, \\ Gastroenterology Section, \\ 111C, VA Medical Center, \\ 5000 W. National Avenue, \\ Milwaukee, WI 53295, USA. \\ Accepted for publication \\ 26 March 1991}

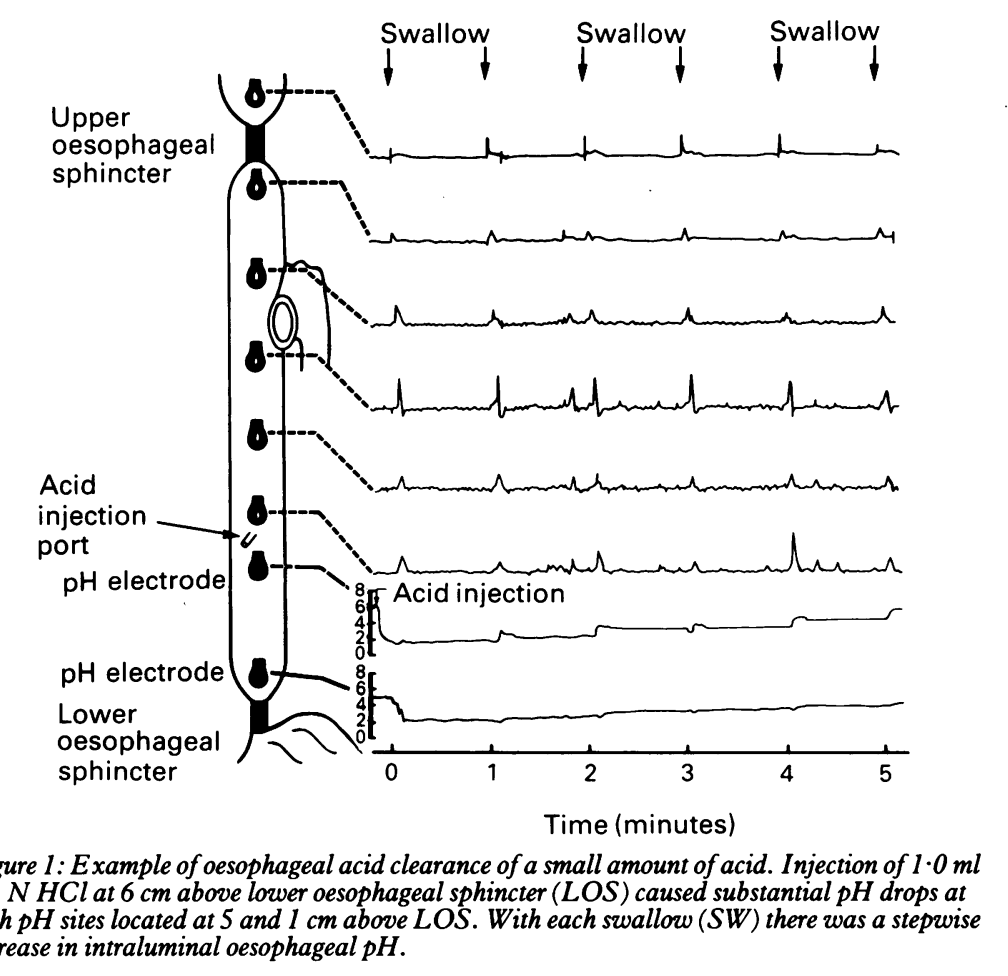

Figure 1: Example of oesophageal acid clearance of a small amount of acid. Injection of $1.0 \mathrm{ml}$ $0 \cdot 1 \mathrm{~N} \mathrm{HCl}$ at $6 \mathrm{~cm}$ above lower oesophageal sphincter (LOS) caused substantial pH drops at both $p H$ sites located at 5 and $1 \mathrm{~cm}$ above LOS. With each swallow (SW) there was a stepwise increase in intraluminal oesophageal $\mathrm{pH}$.

\begin{abstract}
The oesophageal acid clearance time was evaluated in 10 healthy volunteers of 'small' boluses of 0.5 and $1 \mathrm{ml}$ and 'minute' boluses of 0.05 and $0.1 \mathrm{ml} 0.1 \mathrm{~N} \mathrm{HCl}$, as well as 0.1 and $1 \mathrm{ml} \mathrm{0.01}$ and $0.001 \mathrm{~N} \mathrm{HCl}$. Swallow rate was normalised at q 60 seconds. For $0.1 \mathrm{ml} 0.1 \mathrm{~N}$ $\mathrm{HCl}$, acid clearance time was also measured for swallow intervals of $q \mathbf{3 0}$ and 120 seconds. Acid clearance time to restore $\mathrm{pH}$ to 4.0 was significantly longer $(p<0.01)$ for the 0.5 and $1 \mathrm{ml} 0.1 \mathrm{~N} \mathrm{HCl}$ (210 and 273 seconds, respectively) than for the 0.05 and $0.01 \mathrm{ml}$ acid boluses (83 and 94 seconds, respectively). The minimum acid clearance time was 18 seconds $(0.05$ $\mathrm{ml} \mathrm{0.1} \mathrm{N} \mathrm{HCl}$ ). Acid clearance time for $0.1 \mathrm{~N}$ $\mathrm{HCl}$ was less than one minute on only two occasions. The acid clearance times were comparable when the subjects sat upright. A longer interswallow interval - that is, 120 seconds, resulted in a significantly longer acid clearance time than shorter swallow intervals $(\mathbf{p}<0.05)$. Oesophageal acid clearance time for small acid volumes averaged more than three minutes and for minute acid volumes was generally more than one minute; and acid
\end{abstract}

clearance times were comparable for the supine and upright postures, while gastrooesophageal reflux episodes causing $\mathrm{pH}$ drops to 3-4 may last for $<15$ seconds, substantial oesophageal $\mathrm{pH}$ drops to $\leq 1.5$ that persists $<15$ seconds are difficult to be attributed to true gastrooesophageal reflux.

Previous studies indicate that normal oesophageal acid clearance occurs as a two step process: peristalsis rapidly removes the acid volume, and swallowed saliva neutralises the small amount of residual acid that coats the oesophageal mucosa. ${ }^{12}$ These earlier acid clearance studies were generally done by injecting $15 \mathrm{ml}$ boluses of $\mathrm{HCl}$ into the oesophagus, simulating large volume refluxes. ${ }^{2-4}$ Volume and acidity of the gastroesophageal refluxate, however, may vary widely. A recent study of subjects with hiatus hernia suggested that refluxes of small volumes of acid from the hernia contribute to the longer acid clearance time found in this group compared with controls. ${ }^{5}$ Currently, information about acid clearance of small volumes of acid with different acidity is not generally available. Beside physiological implications, such information is needed for interpretation of short duration $\mathrm{pH}$ drops of five to 10 seconds commonly observed during long term oesophageal $\mathrm{pH}$ monitoring. This investigation was designed to address these issues.

\section{Methods}

\section{VOLUNTEERS}

We studied 10 healthy volunteers of either sex aged 24 (5) (SD) years. A specially designed manometric catheter with eight side holes: 1,4 , $7,10,13,18,21$, and $24 \mathrm{~cm}$ from the tip was placed transnasally within the oesophagus so that site 1 was $6 \mathrm{~cm}$ proximal to the lower oesophageal sphincter. When so positioned, this catheter recorded the motor activity of the oesophagus and pharynx at $6,9,12,15,18,23,26$, and $29 \mathrm{~cm}$ from the proximal margin of the lower oesophageal sphincter. Although the catheter was not perfused during the study, the side holes located in the pharynx provided accurate swallow signals and the oesophageal ports recorded oesophageal peristalsis. ${ }^{6}$ Two $\mathrm{pH}$ electrodes (MI-506, Microelectrodes, Inc, Londonderry, $\mathrm{N}$ Ireland $\mathrm{NH}$ 03053) were passed transnasally and positioned 
at 1 and $5 \mathrm{~cm}$, respectively, proximal to the manometrically determined lower oesophageal sphincter. The distal catheter side hole, located $1 \mathrm{~cm}$ orad to the proximal $\mathrm{pH}$ electrode, was used for acid injection (Fig 1 ). We tested acid clearance time for $0.05,0.1,0.5$, and $1 \mathrm{ml} 0.1 \mathrm{~N}$ $\mathrm{HCl}(\mathrm{pH} \mathrm{1} \cdot 2)$. To evaluate the effect of different acidity on the acid clearance time, subsequently, we also evaluated it for 0.1 and $1.0 \mathrm{ml} 0.01 \mathrm{~N}(\mathrm{pH} 2)$ and $0.001 \mathrm{~N}(\mathrm{pH} \mathrm{3}) \mathrm{HCl}$. To deliver each concentration of acid, the designated channel of acid delivery which had a volume of $1 \mathrm{ml}$ was flushed and kept filled with the same acid concentration - that is, $0 \cdot 1 \mathrm{~N}$, $0.01 \mathrm{~N}, 0.001 \mathrm{~N} \mathrm{HCl}$. This technique made it possible to accurately deliver minute amounts of acid into the oesophagus, as injection of the desired volume displaced the equivalent amount from the channel into the oesophagus. Acid injection was done using an insulin syringe when the oesophagus was cleared of flushed acid and intraluminal $\mathrm{pH}$ reached to $\geq 5$ by spontaneous swallows.

Swallow rate was normalised by instructing the subject to swallow every 60 seconds, beginning the first swallow 10 seconds after the acid injection into the oesophagus. Acid boluses were injected 10 seconds after the subjects swallowed spontaneously. To study the effect of the swallow interval on the acid clearance time, acid clearance time for $0 \cdot 1 \mathrm{ml} 0 \cdot 1 \mathrm{~N} \mathrm{HCl}$ was repeated for swallow intervals of 30,60 , and 120 seconds. All acid volumes and normalcies, as well as swallow intervals, were tested in all subjects. Studies were done with the subject in supine position and were repeated at a later date with the subject sitting upright. Acid clearance time was defined as time, in seconds, required for the intraluminal $\mathrm{pH}$ to return to 4 . Manometric

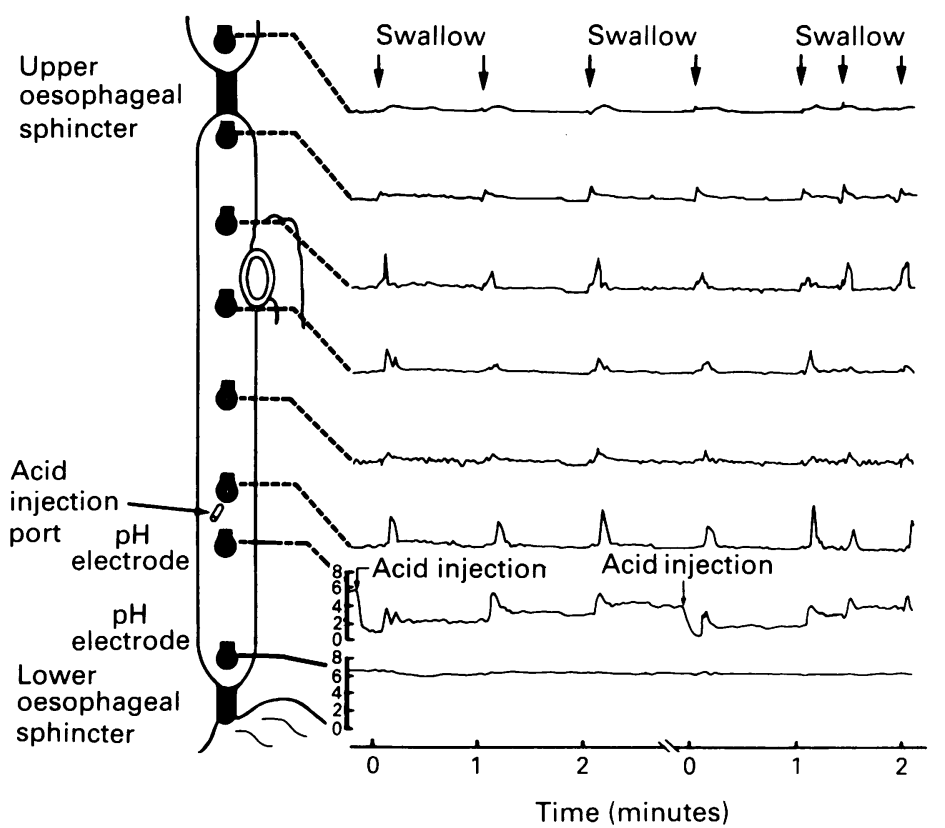

Figure 2: Examples of oesophageal acid clearance of minute amount of acid. Contrary to small amount of acid $(1,0 \cdot 5 \mathrm{ml} 0 \cdot 1 \mathrm{~N} \mathrm{HCl})$ that caused substantial $\mathrm{pH}$ drop at 5 and $1 \mathrm{~cm}$ above lower oesophageal sphincter (LOS). Injection of a minute volume of $0 \cdot 1 \mathrm{ml} 0 \cdot 1 \mathrm{~N} \mathrm{HCl} \mathrm{at} 6 \mathrm{~cm}$ above LOS did not cause any $p H$ drop at $1 \mathrm{~cm}$ above LOS. During the process of oesophageal acid clearance to $\mathrm{pH} 4.0$ at $5 \mathrm{~cm}$ above the LOS, the pH remained $6.5 \mathrm{at} 1.0 \mathrm{~cm}$ above the LOS. Identical findings occurred after a second injection. These findings indicated that acid clearance at $5 \mathrm{~cm}$ above LOS occurred entirely by acid neutralisation without clearance of acid volume. tracings were evaluated for the development of secondary peristalsis caused by acid injection. Data were analysed using paired Student's $t$ test. Averaged values in the text are given as $\mathrm{X}$ (1) SE.

\section{Results}

Injection of all volumes of $0 \cdot 1 \mathrm{~N} \mathrm{HCl}$ caused reproducible $\mathrm{pH}$ drops of $1 \cdot 2-1 \cdot 4$ at $5 \mathrm{~cm}$ above the lower oesophageal sphincter without inducing secondary peristalsis, thus allowing accurate measurements of acid clearance time (Fig 1). Injection of 0.05 and $0.1 \mathrm{ml} 0.1 \mathrm{~N} \mathrm{HCl}$ at this site generally did not cause a $\mathrm{pH}$ drop at $1 \mathrm{~cm}$ above the lower oesophageal sphincter and acid clearance at $5 \mathrm{~cm}$ above occurred without any change in $\mathrm{pH}$ at $1 \mathrm{~cm}$ above lower oesophageal sphincter (Fig 2).

Acid clearance time for 0.5 and $1 \mathrm{ml}$ acid boluses of $0 \cdot 1 \mathrm{~N} \mathrm{HCl}(210$ (28) and 273 (37) seconds, respectively) were significantly longer than acid clearance time for 0.05 and $0.1 \mathrm{ml}$ acid boluses (83 (16) and 94 (10) seconds, respectively) (Fig 3). A minimum acid clearance time of 18 seconds was observed for a $0.05 \mathrm{ml}$ acid volume; otherwise, acid clearance time was generally longer than 60 seconds. Acid clearance times for all acid volumes were similar in the supine and upright position.

Injection of all volumes of 0.001 and $0.01 \mathrm{~N}$ $\mathrm{HCl}$ resulted in inconsistent and variable $\mathrm{pH}$ drops, therefore, reproducible acid clearance time for these minute volumes of higher $\mathrm{pH}$ could not be measured. The shortest acid clearance time observed (18 seconds) occurred for $1 \mathrm{ml} 0.001 \mathrm{~N} \mathrm{HCl}$, after a pH drop to $3 \cdot 2$. Injection of $0.1 \mathrm{ml}$ of $0.01 \mathrm{~N} \mathrm{HCl}$ frequently caused a pH drop to above 4 . At times during the first swallow after this injection, the proximal $\mathrm{pH}$ probe registered a short dip to $\mathrm{pH}$ below 4 which lasted for three to 10 seconds and $\mathrm{pH}$ returned to above 4 by the same swallow (Fig 4 ).

The effect of swallowing rate on acid clearance time is shown in Figure 5. Overall, acid clearance time was inversely related to swallowing rate and a swallow interval of 120 seconds was significantly longer than that for a swallow interval of 30 or 60 seconds.

\section{Discussion}

In this study we evaluated distal oesophageal

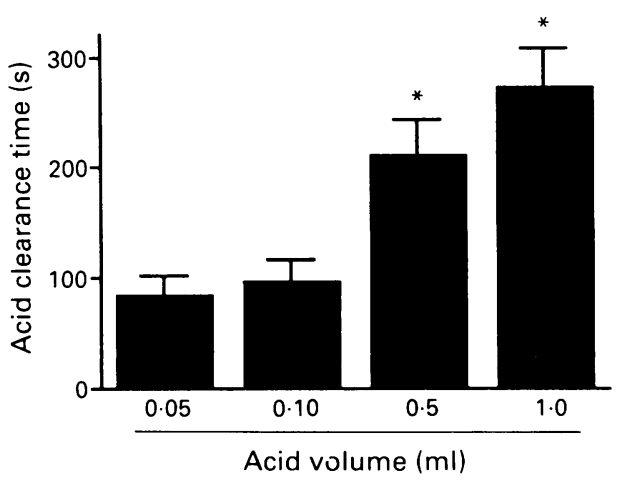

Figure 3: Effect of acid volume on oesophageal acid clearance. Acid clearance time for 0.5 and $1.0 \mathrm{ml}$ of $0.1 \mathrm{~N}$ $\mathrm{HCl}$ was significantly longer $\left({ }^{\star} p<0.05\right)$ than acid clearance time for 0.1 and $0.05 \mathrm{ml} 0.1 \mathrm{~N} \mathrm{HCl}$. 


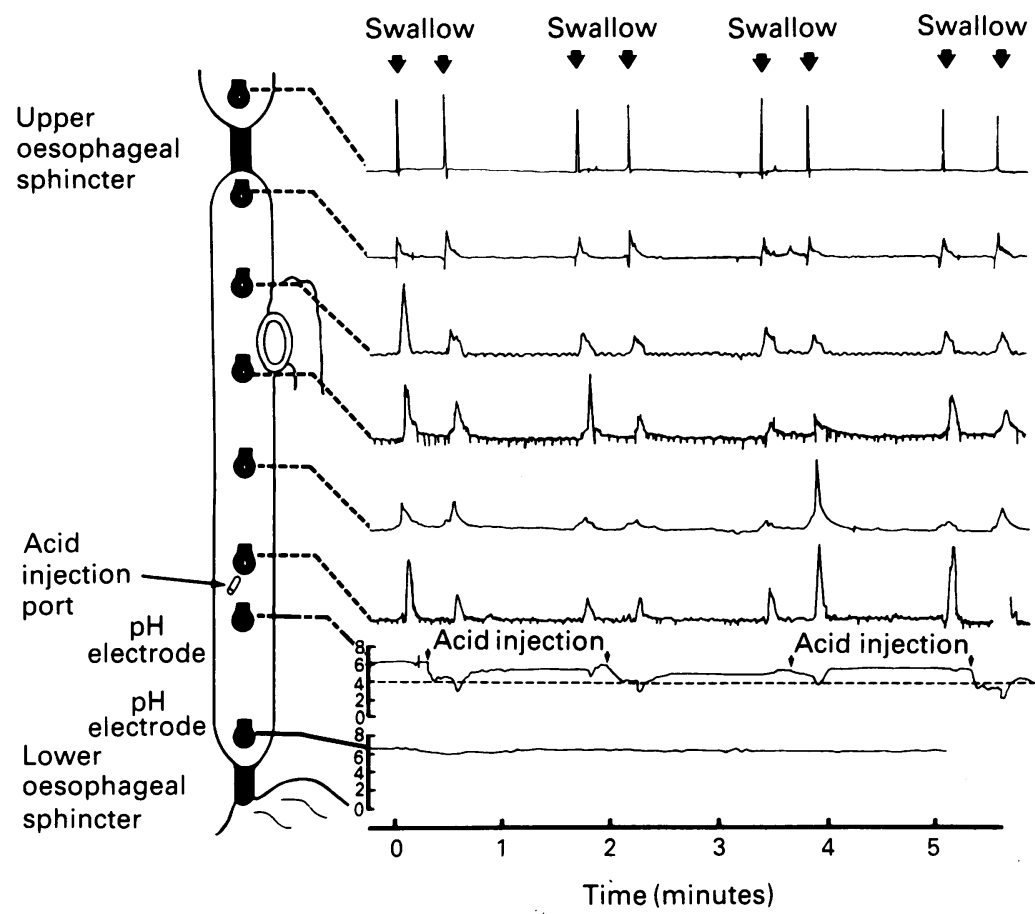

Figure 4: Example of $\mathrm{pH}$ drop to $3 \cdot 7$ that occurred during first swallow after injection of $0 \cdot 1 \mathrm{ml}$ $0.01 \mathrm{~N} \mathrm{HCl}$. These episodes lasted three to $10 \mathrm{~s}$. Acid neutralisation occurred entirely during the same swallow.

clearance of small amounts of acid, designed to simulate gastrooesophageal reflux of small volumes of gastric acid. This simulation was achieved by injecting small $(0.5$ and $1 \mathrm{ml})$ and minute volumes of $(0.05$ and $0.1 \mathrm{ml})$ of 0.001 , $0 \cdot 01$, and $0 \cdot 1 \mathrm{~N} \mathrm{HCl}$ adjacent to a $\mathrm{pH}$ sensor, located $5 \mathrm{~cm}$ above the lower oesophageal sphincter. Although the mode of delivery of acid was different from the pattern of a true gastrooesophageal reflux, it enabled us to measure acid clearance time under a controlled condition for acidity, volume, site, and dwell time.

Intraoesophageal $\mathrm{pH}$ drop at the $\mathrm{pH}$ site close to the injection port for all volumes of $0 \cdot 1 \mathrm{~N} \mathrm{HCl}$ was substantial and reproducible. On the contrary, 0.001 and $0.01 \mathrm{~N} \mathrm{HCl}$ caused inconsistent intraoesophageal $\mathrm{pH}$ drops suggesting that some of the injected acid was neutralised by preexisting intraluminal salivary bicarbonate that coated the oesophageal mucosa.

Acid clearance time for small amounts of $0 \cdot 1 \mathrm{~N}$ $\mathrm{HCl}$, was comparable with acid clearance time for larger volumes of $2-15 \mathrm{ml}$ measured in

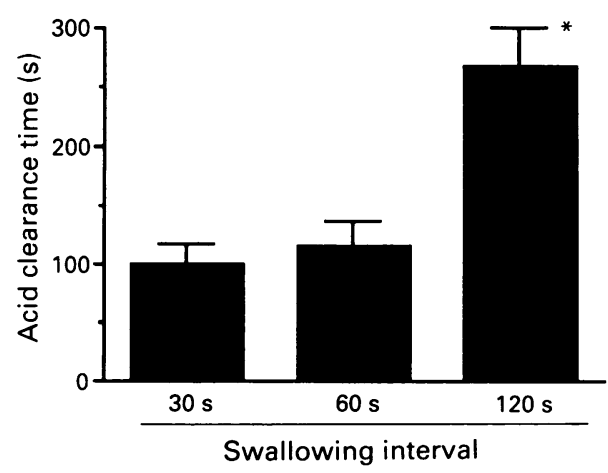

Figure 5: Effect of swallow interval on oesophageal acid clearance of $0.1 \mathrm{ml} 0.1 \mathrm{~N} \mathrm{HCl}$. Acid clearance time was significantly lower $\left({ }^{\star} p<0.05\right)$ when subjects swallowed every 120 s compared with when they swallowed every 30 or $60 \mathrm{~s}$. previous studies. ${ }^{12}$ On the other hand, acid clearance time for minute amounts of $0.1 \mathrm{~N} \mathrm{HCl}$ was significantly shorter than acid clearance time for 0.5 and $1.0 \mathrm{ml}$. The shortest acid clearance time for $0 \cdot 1 \mathrm{~N} \mathrm{HCl}$ found during this study was 18 seconds and only on two occasions was acid clearance time shorter than one minute. These findings suggest that short duration $\mathrm{pH}$ drops on long interval $\mathrm{pH}$ recordings, generally attributed to reflux episodes, are difficult to ascribe to reflux episodes that cause a substantial $\mathrm{pH}$ drop to $\leq 1 \cdot 5$. Such events are likely to be the result of either artifact or refluxates of relatively high $\mathrm{pH}$ - that is, $\mathrm{pH} \mathrm{3-4} \mathrm{and} \mathrm{small} \mathrm{volume} \mathrm{or} \mathrm{short}$ dwell time as shown in Figure 4.

In this study the interval between acid injection and the following swallow was kept constant at 10 seconds, resulting in a fixed aciddwell time before oesophageal peristalsis and salivary sodium bicarbonate reached the acidified $\mathrm{pH}$ probe and oesophageal mucosa. It is conceiveable, however, that during actual gastrooesophageal reflux events the acid dwelling time may vary from the present study and result in a different acid clearance time. Further studies are needed to address this issue.

A thin, obligatory, mucosal fluid layer normally coats the oesophageal mucosa. ${ }^{78}$ During gastrooesophageal acid reflux or oesophageal acid injection, hydrogen ions rapidly enter the thin mucosal fluid layer, thereby rendering it acid even after all the volume of the acid bolus has been cleared from the oesophageal lumen, such as occurs with one or two normal swallows. ${ }^{29}$ Theoretically, the $\mathrm{pH}$ electrode in contact with mucosa, records the $\mathrm{pH}$ of the unstirred layer. On subsequent swallows of saliva, hydrogen ions in the mucosal fluid layer that generate an acid oesophageal $\mathrm{pH}$ are neutralised mainly by two mechanisms. First, bicarbonate ions from saliva ${ }^{10}$ enter the unstirred mucosal fluid layer and neutalise hydrogen ions. Second, hydrogen ions in the mucosal unstirred fluid layer diffuse into saliva bolus where they combine with bicarbonate to form water and are carried away. An incremental acid titration occurs with each swallow of saliva until the oesophageal $\mathrm{pH}$ is restored to that of swallowed saliva. ${ }^{7}$ In this setting, even minute volumes of $0.1 \mathrm{~N} \mathrm{HCl}$ caused a substantial $\mathrm{pH}$ drop - for example $\mathrm{pH}$ to about $1 \cdot 2$. Frequently, minute volumes $(0.05$ and $0.1 \mathrm{ml} 0 \cdot 1 \mathrm{~N} \mathrm{HCl})$ acidified the mucosal fluid layer at the proximal $\mathrm{pH}$ probe, without causing a $\mathrm{pH}$ drop at the distal $\mathrm{pH}$ site located $4 \mathrm{~cm}$ distally. With subsequent swallows, acid clearance occurred in the proximal $\mathrm{pH}$ site without acid being registered as a $\mathrm{pH}$ drop at the distal $\mathrm{pH}$ site, thereby suggesting that 'acid clearance' occurred exclusively by the process of acid neutralisation without volume clearance. In some instances, a small and short duration $\mathrm{pH}$ drop at the distal electrode occurred with the first swallow, thereby indicating that some of the acid clearance occurred by volume clearance.

It has been previously shown that an increase in salivary flow improves acid clearance time, whereas, preventing saliva from reaching the oesophagus increases oesophageal acid clearance time.' A significant increase in acid clearance 
time for $15 \mathrm{ml} 0 \cdot 1 \mathrm{~N} \mathrm{HCl}$ has been reported by Helm et al when the swallow interval was increased from 30 to 60 seconds. In our study, acid clearance time for $0 \cdot 1 \mathrm{ml} 0 \cdot 1 \mathrm{~N} \mathrm{HCl}$ did not change significantly when the swallow interval was increased from 30 to 60 seconds, but increased significantly when subjects swallowed every 120 seconds. We believe the discrepancies between the two studies are caused by the different acid volumes that were tested. An inverse relationship of acid clearance time with swallowing rate found in this study again substantiates the importance of saliva and its neutralising capacity in oesophageal acid clearance time.

Supported in part by USPHS grant No. RO1 DK25731 and National Research Service Award \#5-T32-AM07267. This work was presented in part in a poster session at the American Gastroenterological Association Meetings in San Francisco during Digestive Disease Week, May 1986 and abstracted in Gastroenterology 1986; 90 no 5 (Pt 2): 1628.
1 Helm JF, Dodds WJ, Riedel DR, Teeter BC, Hogan WJ, Arndorfer RC. Determinants of esophageal acid clearance in normal subjects. Gastroenterology 1983; 85: 607-12.

2 Helm JF, Dodds WJ, Hogan WJ, Palmer DW, Teeter BC Effect of esophageal emptying and saliva on clearance of acid from the esophagus. $N$ Engl f Med 1984; 310: 284-8.

3 Booth DJ, Kemmerer WT, Skinner DB. Acid clearing from the distal esophagus. Arch Surg 1968; 96: 731-4.

4 Kjellen G, Tibling L. Influence of body position, dry and water swallows, smoking, and alcohol on esophageal acid water swallows, smoking, and 1978; 13: 283-8.

5 Mittal RK, Lange RC, McCallum RW. Identification and mechanism of delayed esophageal acid clearance in and mechanism of delayed esophageal acid clearance in subjects

6 Dent J, Dodds WJ, Friedman RH, Sekiguchi T, Hogan WJ, Arndorfer RC. Mechanism of gastroesophageal reflux in recumbent asymptomatic human subjects. $\mathcal{F}$ Clin Invest 1980; 65: 256-67.

7 Teeter BC, Helm JF, Dodds WJ, et al. Computerized model of the mechanisms governing esophageal acid clearance [Abstract]. Dig Dis Sci 1982; 27: 664 .

8 Dodds WJ. The pathogenesis of gastroesophageal reflux disease. Am F Radiol 1988; 151: 49-56.

9 Dodds WJ, Hogan WJ, Helm JF, Dent J. Pathogenesis of reflux oesophagitis. Gastroenterology 1981; 81: 376-94.

$10 \mathrm{Helm}$ JF, Dodds WJ, Hogan WJ, Soergel KH, Egide MS Wood CM. Acid neutralizing capacity of human saliva. Gastroenterology 1982; 83: 69-74. 